\title{
A mouse model for oral squamous cell carcinoma
}

\author{
Remilio A. L. Schoop • Mathieu H. M. Noteborn • \\ Robert J. Baatenburg de Jong
}

Received: 1 April 2009/Accepted: 23 July 2009/Published online: 14 August 2009

(C) The Author(s) 2009. This article is published with open access at Springerlink.com

\begin{abstract}
Despite recent advances, the prognosis of oral squamous cell carcinoma is still poor. Therapeutic options such as radiotherapy, chemotherapy, surgery and the novel treatment option gene therapy are being investigated in animal models. Diverse models have been studied to induce oral squamous cell carcinomas. The carcinogenic 4-nitroquinoline-1-oxide (4NQO) model has proven to be successful although until now it is unknown at what time point the established tumor is a representative squamous cell carcinoma and has a suitable volume for scientific treatment. For this end we applied 4NQO 3 times a week during 16 weeks and measured the volume of tumor tissue each week until the end of the experiment at 40 weeks. Concurrent histopathology at different time points up to the end of the experiment revealed that all mice bearing oral tumors were diagnosed with squamous cell carcinoma. Immunohistochemistry with markers cyclin D1 and E-cadherin revealed that the generated mouse oral tumors showed strong similarities with the described immunopathology in human oral tumors. The $4 \mathrm{NQO}$ model is a
\end{abstract}

R. A. L. Schoop

Department of Otolaryngology and Head and Neck Surgery, Leiden University Medical Center, Leiden, The Netherlands e-mail: r.a.1.schoop@lumc.nl

M. H. M. Noteborn

Leiden Institute of Biological Chemistry, Leiden University, Leiden, The Netherlands

R. J. Baatenburg de Jong $(\bowtie)$

Department of Otolaryngology and Head and Neck Surgery, Erasmus Medical Center, Rotterdam, The Netherlands

e-mail: r.j.baatenburgdejong@erasmusmc.nl

R. J. Baatenburg de Jong

Dr. Molewaterplein 40, 3000 CA Rotterdam, The Netherlands suitable alternative for preclinical gene therapy experiments with primary oral tumors. Future survey of therapeutic options in the carcinogenic 4 NQO model should be conducted around 40 weeks after the start of the treatment.

Keywords 4-Nitroquinoline-1-oxide · Gene therapy · Immunocompetent mice - Tumor volume .

Squamous cell carcinoma of head and neck

\section{Introduction}

Oral cancer accounts for almost 275,000 new cases worldwide each year (Parkin et al. 2005). The main risk factors for developing oral cancer are tobacco smoking and consumption of alcohol (Boffetta and Hashibe 2006). Continuation of smoking during treatment can lead to increased morbidity and mortality (Videtic et al. 2003). Primary treatment is associated with high morbidity and function loss of the organ, while up to 50\% die due to recurrence (Monnerat et al. 2002). Present-day treatment, surgery, radiotherapy or chemotherapy or a combination of these three, has had notwithstanding the improvements, no significant improvement in survival (Cooper et al. 2004). For that reason new treatments, such as (targeted) gene therapy are being developed (Ganesh et al. 2008; Ghobrial et al. 2005; Loeffler-Ragg et al. 2008; Schoop et al. 2004; 2008).

New therapies can be investigated both in vitro and in vivo. The drawback of in vitro laboratory study is the dissimilarity between the cell culture and the physiological processes giving misleading results. Several animal models for oral squamous cell carcinoma are used including hamster, rat and mouse models, with each model having its own advantages and disadvantages. Earlier experiments were set to induce tumors by mechanical damaging the jaw 
in mice (Eulderink 1972). Nowadays xenograft models are widely used. In this model human cells are injected and grow in immunodeficient mice. Advantages are the speed and certainty of tumor development. The premier limitation is the lack of functional $\mathrm{T}$ lymphocytes in nude mice resulting in a non physiological tumor response.

The widely used hamster cheek pouch model in which 7,12-dimethlbenz(a)anthrance is used to induce tumors has a disadvantage because the tumors are unalike the human counterparts (Kanojia and Vaidya 2006). After the introduction of 4-nitroquinoline-1-oxide (4-NQO) for inducing tumors in rats (Wallenius and Lekholm 1973), it has been extensively used in both rats and mouse and can useful for analyzing the effects of anti-tumor agents (Suzuki et al. 2006). The 4 NQO oral squamous cell carcinoma model is a lengthy multi-step process in which eventual invasive squamous cell carcinoma is attained after several months.

Once established the tumors are suitable for studying the therapeutic effect of various therapies including gene therapy. Intratumoral injection of recombinant adeno-viral vectors is mainly used in preclinical models (St George 2003). Therefore at the time of injection a minimum tumor volume must be attained and the realization of squamous cell carcinoma must be assured. Up till now, in the 4NQO mouse model, this time point is unknown.

The present study was set up to investigate the time needed for sufficient tumor volume to be developed enabling intra-tumoral injection of anticancer agents such as gene therapy. As important, we have identified that the generated mouse oral tumors resembles human oral tumor formation.

\section{Materials and methods}

Animals and treatment with carcinogen

Thirty-two 7- and 8-weeks-old male CBA mice weighing between 23 and $27 \mathrm{~g}$ were purchased from Harlan in Zeist, The Netherlands. The experiments were approved in advance by the Leiden University Animal Welfare Committee. All animals were kept at standard laboratory conditions of alternating 12-h periods of light and darkness and were fed sterilized laboratory chow and water ad libitum. The carcinogen 4-nitroquinoline-1-oxide (Fig. 1) was dissolved in propylene glycol to a final concentration of $5 \mathrm{mg} / \mathrm{ml}$. For each session a fresh aliquot was used. Anesthesia was achieved by inhalation of halothane vapour and the tongue was stroked once with a no 3 camel hair brush (Hawkins et al. 1994), which had been dipped in the $4 \mathrm{NQO}$ solution. The mice were restrained from drinking the first hour after 4NQO application. The mice were treated with $4 \mathrm{NQO}$ during 16 weeks with a frequency of 3
Fig. 1 Chemical structure of 4-nitroquinoline 1-oxide (4NQO)

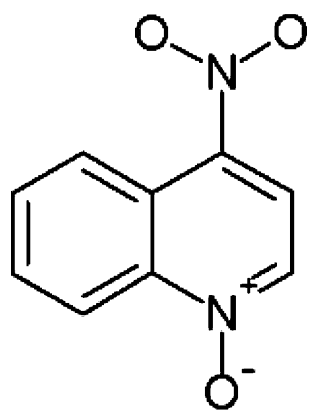

weekly treatments. All mice were carefully inspected daily and weighed weekly.

Pathological examination and immunohistochemistry

After the final 4NQO application the oral mucosa of each individual mouse was examined under inhalation anesthesia every week. The volume of exophytic tumors was calculated each week by measuring three dimensions (length, height and width). After 24 weeks following the start of the experiment 6 mice were sacrificed and tongue tissue was removed and fixed in freshly made $4 \%$ buffered formalin. Subsequently there were groups of 6 mice sacrificed after 28, 32, 36 and 40 weeks.

After paraffin-embedding, serial sections of $4 \mu \mathrm{m}$ width were made and one in five subsequent sections were stained with hematoxylin-eosin (HE). The epithelia was examined by a pathologist in our institution and classified as either normal epithelia, mild dysplasia, moderate dysplasia, sever dysplasia or invasive squamous cell carcinoma. Dysplastic epithelia and invasive squamous cell carcinoma were subsequently investigated by immunohistochemistry with cyclin D1 and E-cadherin. The following antibodies were used from Santa Cruz Biotechnology, Inc. (Santa Cruz, CA): the rabbit polyclonal antibody against cyclin D1 (H-295, dilution 1:100) and a rabbit polyclonal antibody against E-cadherin (H-108, dilution 1:50). After the slides were deparaffinized and rehydrated, antibodies were applied according to the manufacture's protocol.

\section{Results}

Histological findings

The first macroscopic changes were seen 19 weeks after starting the experiment. After 24 weeks some tongues did not show any pathological changes (Fig. 2a) although at the same phase hyperplasia without atypia and mild dysplastic changes were detected (Fig. 2b). Four weeks further on, advance in atypia was found and moderate (Fig. 2c) 

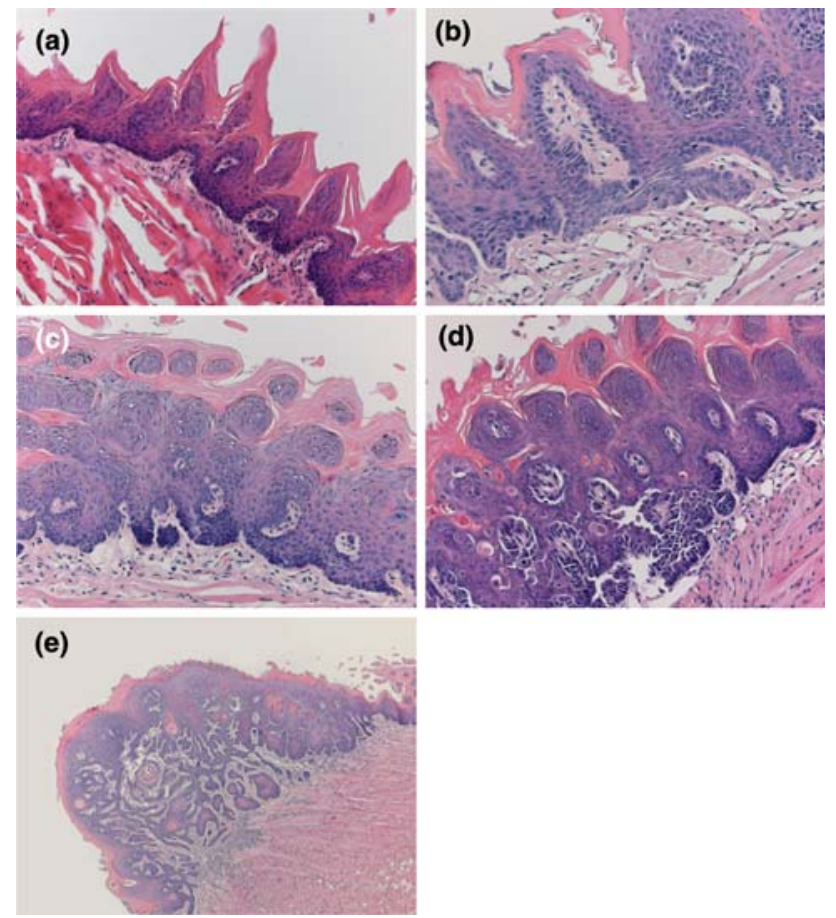

Fig. 2 Histological findings of tongue in mice treated with 4NQO during 16 weeks. a Normal tongue with no histopathological changes 24 weeks after starting the experiment. b Mild dysplasia after 24 weeks. c Moderate dysplasia after 28 weeks. d Severe dysplasia after 28 weeks. e Invasive squamous cell carcinoma after 32 weeks. Original magnification $\times 10$

and severe dysplasia (Fig. 2d) could be detected. The first evidence of squamous cell carcinoma was identified after 32 weeks (Fig. 2e). At the time point of 36 weeks 4 out of 6 animals that were sacrificed showed squamous cell carcinoma at histopathological examination. At 40 weeks, the end of our experiment, all 6 tumors were squamous cell carcinomas (data not shown).

\section{Immunohistological findings}

Once all 6 mice bearing tumors at the 40 weeks time point were diagnosed with squamous cell carcinoma, immunohistochemistry was performed. A comparison of Cyclin D1 and E-cadherin expression was made in squamous cell carcinoma detected after 40 weeks and mild dysplasia established after 24 weeks. Immunohistological evaluation was done in the tumors of our interest. Cyclin D1 expression was investigated by assessing the nuclear staining of the antigen. Only nuclear staining was considered positive, while cytoplasmatic staining was regarded as negative. Mild dysplasia exposed predominantly basal cells expressing cyclin D1 (Fig. 3c). The stainability increased with the progression from dysplasia to carcinoma and the positive ratio was the highest in the squamous cell carcinoma (Fig. 3d). After 40 weeks, squamous cell carcinoma


Fig. 3 Histopathology and immunohistochemistry staining with biomarkers cyclin D1 and E-cadherin. The left panel shows mild dysplasia after 24 weeks, the right panel shows squamous cell carcinoma after 40 weeks. Hematoxylin-eosin staining (HE) of mild dysplasia (a) and of squamous cell carcinoma (b) are shown. Cyclin D1 is primarily expressed in basal cells in mild dysplasia (c) and throughout the tumor and in tumor nests in squamous cell carcinoma (d). E-cadherin is expressed in the parabasal cell layer of the epithelium, but not on the surface of basal cells in mild dysplasia (e) and is partly lost in the invasive front of squamous cell carcinoma (f). Original magnification $\times 4$

showed a distribution throughout the tumor (Fig. 3d) as well as the basal cell layer and lower spinous cells.

Staining of the tongue after 24 weeks showed that E-cadherin was strongly expressed in the parabasal cell layer, but not on the surface of basal cells (Fig. 3e). In the oral squamous carcinoma we noticed a loss of E-cadherin expression in the invasive front and positive staining of cancer cell nests (Fig. 3f).

\section{Tumor volume}

The initial measurement of a volume of exophytic tumor was done after 20 weeks following the start of the experimental procedure. By measuring the size of the tumor in three dimensions the volume was calibrated in $\mathrm{mm}^{3}$ by using the following formula: $V=l \times w \times h$. The volumes and ranges of each time point are shown in Fig. 4. After 20 weeks, the average volume was $6 \mathrm{~mm}^{3}$ with a range of $2-12 \mathrm{~mm}^{3}$. Gradually with time the volume increased and reached $30 \mathrm{~mm}^{3}$ at the 40 weeks time point. 


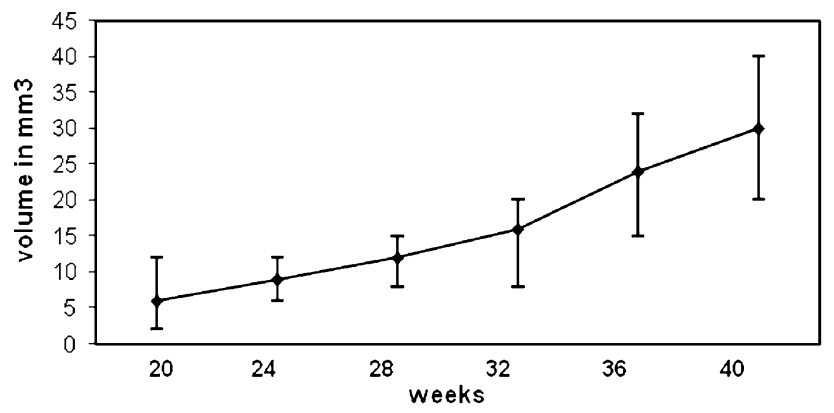

Fig. 4 Volume of established tumors. Tumors were measured in three dimensions and the volume was calibrated in $\mathrm{mm}^{3}$. The volumes and ranges of each time point after the start of the treatment are shown

\section{Discussion}

Oral squamous cell carcinoma is one of the most common cancers in the world. Novel treatment is best studied in animal models that mimic the same clinical features as human squamous cell carcinomas.

In this study we induced oral squamous cell carcinomas by applying 4NQO oraly during 16 weeks in mice. Premalignant laesions appeared 3 weeks after the last application of $4 \mathrm{NQO}$. The typical tumor progression for squamous cell carcinoma was seen before invasive squamous cell carcinomas appeared. At 36 weeks two-thirds of the tumors were squamous cell carcinomas, 4 weeks further all 6 oral tumors were squamous cell carcinomas. These results are in accordance with earlier observed results in which squamous cell carcinomas were detected between 12 and 33 weeks after applying 4NQO during 16 weeks (Hawkins et al. 1994; Tang et al. 2004).

Immunohishtochemistry was performed on the tissues to assess the similarities with human squamous cell carcinoma. Biomarkers have been studied to predict behaviour of tumor cells and are used to characterise tumors (Takes 2004). Cyclin D1 plays a pivotal role in transition from $G_{1}$ to $\mathrm{S}$ phase and cyclin $\mathrm{D} 1$ expression pattern is associated tumor characteristics and survival (Bova et al. 1999). As is seen in human and other animal models (Niwa et al. 2001; Yoshida et al. 2005) cyclin D1 expression showed an increased expression in the oral squamous cell carcinoma in our mice. E-cadherin, a calcium dependent membrane protein that is essential for the formation of adherens junction between cells. There is a connection with changing expression of E-cadherin and the transition from hyperplasia to invasive carcinoma (Perl et al. 1998). We observed less expression of E-cadherin in invasive section of the carcinoma and evenly distributed expression in earlier stages, a pattern that has been reported earlier in human oral squamous cell carcinoma (Williams et al. 1998).

Average tumor volume advanced from $6 \mathrm{~mm}^{3}$ after 20 weeks to $30 \mathrm{~mm}^{3}$ at the 40 weeks time point. For intratumor injection with an adenovirus it is desirable that the size of each axe of the tumor is at least $2 \mathrm{~mm}$, though preferable higher. Eventual tumor size reduction after treatment is then feasible. Assuming that the 4NQO oral tumor model will not have the prospect to develop in to a large tumor volume such as the model in which tumor cells are injected subcutaneously in the flank, tumor volume will not easily exceed $100 \mathrm{~mm}^{3}$. Previous experiments with intra-tumor injection of gene therapy showed that the injected volume must not surpass $30 \%$ of the volume of the tumor (van der Eb et al. 2002). Taking this in to account and knowing that the volume of an oral squamous cell carcinoma in mice is small we estimate that a tumor volume of at least $15 \mathrm{~mm}^{3}$ is desirable. After 32 weeks the tumor volume surpassed this point and after 40 weeks the volume averaged $30 \mathrm{~mm}^{3}$. We estimate that a desirable tumor volume will be reached after these 40 weeks and the histopathology will reveal a squamous cell carcinoma, without hampering the animal's welfare.

The two most frequent used experimental procedures for investigating therapies are in vitro cell lines and the nude mouse. The 4NQO model has several advantages and disadvantages over these laboratory experiments. Compared with the cell lines and the nude mouse model, the close similarity of the 4NQO model to the physiological process is a big benefit. The biggest drawback of the nude mouse model is the lack of an immunocompetent component. The weakness of the hamster cheek pouch model is the earlier mentioned dissimilarity of the tumors with the human equivalent. Application of DMBA causes an inflammatory response and necrosis making it hard to study early squamous lesions (Nauta et al. 1996). No inflammatory reaction or necrosis was seen in our specimens. Other drawbacks of this model are that the cheek pouch has no anatomic counterpart in human, the epithelium of the cheek pouch is significantly thinner than other parts of the oral mucosa of humans and mice and the tumors seem to progress from papillomas (MacDonald 1981; Nauta et al. 1995), which is uncommon in humans and was not seen in our samples. The clear disadvantage of the 4NQO model is that both the cell line and the nude mouse are less time consuming and that cell line experiments are less costly and most of the time readily available.

In our conclusion taking both advantages and disadvantages in to account the $4 \mathrm{NQO}$ oral tumor model has clear benefits and seems suitable for therapeutic research applications. 
Open Access This article is distributed under the terms of the Creative Commons Attribution Noncommercial License which permits any noncommercial use, distribution, and reproduction in any medium, provided the original author(s) and source are credited.

\section{References}

Boffetta P, Hashibe M (2006) Alcohol and cancer. Lancet Oncol 7(2):149-156

Bova RJ, Quinn DI, Nankervis JS, Cole IE, Sheridan BF, Jensen MJ, Morgan GJ, Hughes CJ, Sutherland RL (1999) Cyclin D1 and p16INK4A expression predict reduced survival in carcinoma of the anterior tongue. Clin Cancer Res 5(10):2810-2819

Cooper JS, Pajak TF, Forastiere AA, Jacobs J, Campbell BH, Saxman SB, Kish JA, Kim HE, Cmelak AJ, Rotman M, Machtay M, Ensley JF, Chao KS, Schultz CJ, Lee N, Fu KK (2004) Postoperative concurrent radiotherapy and chemotherapy for high-risk squamous-cell carcinoma of the head and neck. N Engl J Med 350(19):1937-1944

Eulderink F (1972) Experimental mesenchymal jaw tumors in mice. Ned Tijdschr Geneeskd 116(21):903-904

Ganesh S, Gonzalez-Edick M, Gibbons D, Ge Y, Vanroey M, Robinson M, Jooss K (2008) Combination therapy with radiation or cisplatin enhances the potency of Ad5/35 chimeric oncolytic adenovirus in a preclinical model of head and neck cancer, Cancer Gene Ther

Ghobrial IM, Witzig TE, Adjei AA (2005) Targeting apoptosis pathways in cancer therapy. CA Cancer J Clin 55(3):178-194

Hawkins BL, Heniford BW, Ackermann DM, Leonberger M, Martinez SA, Hendler FJ (1994) 4NQO carcinogenesis: a mouse model of oral cavity squamous cell carcinoma. Head Neck 16(5):424-432

Kanojia D, Vaidya MM (2006) 4-Nitroquinoline-1-oxide induced experimental oral carcinogenesis. Oral Oncol 42(7):655-667

Loeffler-Ragg J, Schwentner I, Sprinzl GM, Zwierzina H (2008) EGFR inhibition as a therapy for head and neck squamous cell carcinoma. Expert Opin Investig Drugs 17(10):1517-1531

MacDonald DG (1981) Comparison of epithelial dysplasia in hamster cheek pouch carcinogenesis and human oral mucosa. J Oral Pathol 10(3):186-191

Monnerat C, Faivre S, Temam S, Bourhis J, Raymond E (2002) End points for new agents in induction chemotherapy for locally advanced head and neck cancers. Ann Oncol 13(7):995-1006

Nauta JM, Roodenburg JL, Nikkels PG, Witjes MJ, Vermey A (1995) Comparison of epithelial dysplasia-the 4 NQO rat palate model and human oral mucosa. Int J Oral Maxillofac Surg 24(1 Pt 1): $53-58$

Nauta JM, Roodenburg JL, Nikkels PG, Witjes MJ, Vermey A (1996) Epithelial dysplasia and squamous cell carcinoma of the Wistar rat palatal mucosa: 4NQO model. Head Neck 18(5):441-449
Niwa S, Ueno S, Shirasu R (2001) Alteration of pRb expression in the development of rat tongue carcinoma induced by 4-nitroquinoline 1-oxide. Oral Oncol 37(7):579-585

Parkin DM, Bray F, Ferlay J, Pisani P (2005) Global cancer statistics, 2002. CA Cancer J Clin 55(2):74-108

Perl AK, Wilgenbus P, Dahl U, Semb H, Christofori G (1998) A causal role for E-cadherin in the transition from adenoma to carcinoma. Nature 392(6672):190-193

Schoop RA, Kooistra K, Baatenburg de Jong RJ, Noteborn MH (2004) Bcl-xL inhibits p53- but not apoptin-induced apoptosis in head and neck squamous cell carcinoma cell line. Int J Cancer 109(1):38-42

Schoop RA, Baatenburg de Jong RJ, Noteborn MH (2008) Apoptin induces apoptosis in an oral cancer mouse model. Cancer Biol Ther 7(9):1368-1373

St George JA (2003) Gene therapy progress and prospects: adenoviral vectors. Gene Ther 10(14):1135-1141

Suzuki R, Kohno H, Suzui M, Yoshimi N, Tsuda H, Wakabayashi K, Tanaka T (2006) An animal model for the rapid induction of tongue neoplasms in human c-Ha-ras proto-oncogene transgenic rats by 4-nitroquinoline 1-oxide: its potential use for preclinical chemoprevention studies. Carcinogenesis 27(3):619-630

Takes RP (2004) Staging of the neck in patients with head and neck squamous cell cancer: imaging techniques and biomarkers. Oral Oncol 40(7):656-667

Tang XH, Knudsen B, Bemis D, Tickoo S, Gudas LJ (2004) Oral cavity and esophageal carcinogenesis modeled in carcinogentreated mice. Clin Cancer Res 10(1 Pt 1):301-313

van der Eb MM, Pietersen AM, Speetjens FM, Kuppen PJ, van de Velde CJ, Noteborn MH, Hoeben RC (2002) Gene therapy with apoptin induces regression of xenografted human hepatomas. Cancer Gene Ther 9(1):53-61

Videtic GM, Stitt LW, Dar AR, Kocha WI, Tomiak AT, Truong PT, Vincent MD, Yu EW (2003) Continued cigarette smoking by patients receiving concurrent chemoradiotherapy for limitedstage small-cell lung cancer is associated with decreased survival. J Clin Oncol 21(8):1544-1549

Wallenius K, Lekholm U (1973) Oral cancer in rats induced by the water-soluble carcinogen 4-nitrochinoline $\mathrm{N}$-oxide. Odontol Revy 24(1):39-48

Williams HK, Sanders DS, Jankowski JA, Landini G, Brown AM (1998) Expression of cadherins and catenins in oral epithelial dysplasia and squamous cell carcinoma. J Oral Pathol Med 27(7):308-317

Yoshida K, Tanaka T, Hirose Y, Yamaguchi F, Kohno H, Toida M, Hara A, Sugie S, Shibata T, Mori H (2005) Dietary garcinol inhibits 4-nitroquinoline 1-oxide-induced tongue carcinogenesis in rats. Cancer Lett 221(1):29-39 